\title{
Urdimento
}

Revista de Estudos em Artes Cênicas E-ISSN: 2358.6958

\section{Das origens ao circo-teatro: mutabilidade e permanência do melodrama}

Cristina Alves de Macedo Eliene Benício Amancio Costa

\section{Para citar este artigo:}

MACEDO, Cristina Alves de; COSTA, Eliene Benício Amancio. Das origens ao circo-teatro: mutabilidade e permanência do melodrama. Urdimento, Florianópolis, v. 3, n. 39, nov./dez. 2020.

DOI: http:/dx.doi.org/10.5965/14145731033920200205

Este artigo passou pelo Plagiarism Detection Software | iThenticate 
Das origens ao circo-teatro: mutabilidade e permanência do melodrama

\author{
Cristina Alves de Macedo ${ }^{1}$
}

Eliene Benício Amancio Costa²

\begin{abstract}
Resumo
Neste artigo, tratou-se sobre o melodrama trazendo considerações a respeito de sua origem até a sua presença no circo-teatro. É um estudo bibliográfico, com destaque para autores italianos que tratam da ópera como melodrama. Em relação ao circo-teatro brasileiro, foram citadas pesquisas relevantes sobre sua criação e sobre como o gênero melodrama destacase como exemplo de dramaturgia que vai preponderar neste formato de circo.
\end{abstract}

Palavras-chave: Melodrama. Ópera. Teatro. Circo-Teatro.

\title{
From origins to circo-theatre: malleability and permanence of melodrama
}

\begin{abstract}
In this article, was discussed about melodrama, considering your origin until its presence in the circus-theater. It's a bibliographic study, with highlight on Italian authors that study the opera as melodrama. In relation to the Brazilian circus-theater, relevant research was cited about its creation and how the melodrama genre is an example of dramaturgy that will predominate in this circus format.
\end{abstract}

Keywords: Melodrama. Opera. Theater. Circus-Theater.

De los orígenes al circo-teatro: mutabilidad y permanencia del melodrama

\section{Resumen}

En este artículo, se trató del melodrama trayendo consideraciones sobre su origen hasta su presencia en el circo-teatro. Se trata de un estudio bibliográfico, con énfasis en autores italianos que tratan la ópera como melodrama. En relación al circo-teatro brasileño, se citaron investigaciones relevantes sobre su creación y sobre cómo el género melodramático se destaca como ejemplo de dramaturgia que predominará en este formato circense.

Palabras clave: Melodrama. Ópera. Teatro. Circo-Teatro.

\footnotetext{
1 Doutoranda no Programa de Pós-Graduação em Artes Cênicas da Universidade Federal da Bahia PPGAC/UFBA. Mestrado em Estudo de Linguagens pela Universidade do Estado da Bahia - UNEB. Integra os grupos de pesquisa Núcleo de Estudos em Teatro Popular da UFBA e O circo e o riso da UNESP. Assistente de edição da Revista Repertório do PPGAC/UFBA. Artista e produtora na empresa Taturana Circus. johnecristina@yahoo.com.br

2 Professora Titular (2015) do Departamento de Técnicas do Espetáculo da Escola de Teatro da Universidade Federal da Bahia. Estágio Sênior na Manchester Metropolitan University (UK) e Université Paris Nanterre (FR) anos de 2017-2018. Pós-doutorado (2009) pelo Instituto de Artes da UNESP (IA/UNESP). Tem doutorado (1999) e mestrado (1993) pela Escola de Comunicações e Artes da Universidade de São Paulo (ECA/USP). elienebenicio@gmail.com
} 


\section{MÉLOS ( $\mu \varepsilon ́ \lambda o \sigma)$ - DRAMA $(\delta \rho \alpha ́ \mu \alpha)$}

Problemas que tocaram a expressividade se tornaram o cerne para muitos teóricos e artistas começarem a estudar possibilidades de solução e modificações estéticas que culminaram com a constituição do melodrama ainda no século XVI.

A insistência na ideia de que a música podia tanto provocar emoções quanto imitar essas emoções de maneira sublime, como já feita em tempos antigos, foi determinante para que diferentes estudiosos focalizassem a atenção naquilo que pudesse ressaltar mormente a expressão e a emoção.

Assim, na busca de criar uma nova musicalidade que se distanciasse da rigidez da música religiosa e pudesse ser uma expressão autêntica e direta do humanismo e do renascimento, o conde Giovanni Bardi organizou uma associação que ficou conhecida como Camerata dei Bardi (final do século XVI), ou Camerata Fiorentina, da qual fazia parte um restrito grupo de mecenas e humanistas, entre os quais se podem citar, como indicado por Massimo Mila (1977), o poeta Ottavio Rinuccine, os músicos Jacopo Peri, Giulio Caccini, Emilio Cavalieri, o literato e musicólogo Vincenzo Galilei, pai do cientista Galileu Galilei.

Os letrados aristocratas da Camerata Fiorentina investiram no estudo da literatura e da música se inspirando no estilo dramático competente à época do teatro grego e acabaram provocando uma inovação cênica ao montar um espetáculo onde a apresentação de cenas teatrais eram enriquecidas com falas melódicas, canto, música e dança.

Paolo Balboni (2016) quando fala sobre o melodrama na Itália de 1600, contesta essa informação ao dizer que os primeiros melodramas constituíram apenas a evolução de um tipo de espetáculo já muito difundido nas cortes, onde as encenações de textos teatrais muito curtos, na maioria das vezes escritos pelos próprios aristocratas, eram incrementadas com a música, não apenas como forma de preencher espaços ociosos, mas também para acompanhar as danças, os cantos de personagens que faziam monólogos ou duetos, dando maior densidade à trama. 
Como se pode observar, quando o assunto recai sobre questões que remontam ao surgimento do melodrama, é complicado estabelecer uma concordância unívoca, mas vale considerar as ponderações de Solerti (1904) quando atribui o mérito da constituição desse gênero a três músicos que se empenharam em desenvolver experimentações, sempre motivados com a perspectiva da tragédia grega, que culminaram em significativas modificações no campo artístico:

Primeiro o Caccini renovou com a nova técnica de canto e com expressão os madrigais e as canções; depois Cavalieri foi o primeiro a aplicar esse método, mas sempre com canto falado, em toda uma representação, embora breve; por último, Peri renovou decididamente a música com a representação e aplicou em uma inteira pastoral, criando o melodrama. (Solerti, 1904, p. 58). ${ }^{3}$

A primeira obra reconhecida como melodrama chama-se Euridice, escrita por Ottavio Rinuccini com música de Jacopo Peri e Giulio Caccini, e foi composta por ocasião do casamento de Maria de Médici com Enrico IV da França, em 05 de outubro de 1600. O referido conúbio aconteceu na Itália e se destacou pela grandiosidade das comemorações que contou com uma série de celebrações no Palazzo Vecchio e as famosas cenografias de Bernardo Buontalenti.

A cerimônia iniciou-se com uma missa solene e músicas na Catedral de Florência e seguiu-se com a realização de um grande banquete onde aconteceu a representação de Una Contesa tra Giunone e Minerva, de Battista Guarini com música de Emilio Cavalieri. A fábula dramática Euridice foi encenada no Palazzo Pitti no segundo dia de celebração, 06 de outubro de 1600, data que marca, convencionalmente, o nascimento do melodrama, mesmo que alguns autores indiquem a ópera ${ }^{4}$ Dafne, composta por Rinuccini e Peri ainda em 1599, como o marco para o surgimento do gênero, como corrobora Solerti (1904).

${ }^{3}$ Prima il Caccini rinnovò con la nuova tecnica del canto e con l'espressione i madrigali e le canzoni; poi il Cavalieri applicò per primo tal metodo, ma sempre con canto spiegato, a tutta una rappresentazione, per quanto breve; ultimo il Peri rinnovò decisamente la musica col recitativo e l'applicò ad una intera pastorale, creando il melodramma. (Solerti, 1904, p. 58 - Tradução nossa).

${ }^{4}$ A palavra ópera, em tradução livre, além de um gênero musical dramático significa também, de maneira genérica, obra na língua italiana. 
Assim, um cavalheiro mecenas oferecia às suas próprias custas à corte dos Médici, não apenas aquela vez, aquele espetáculo que nobres intelectuais com estudos incansáveis e com amor vivo pela arte haviam assiduamente procurado há mais de dez anos: na noite de 21 de janeiro de 1599 permaneceu dali em diante a data precisa para a representação do primeiro melodrama. (Solerti, 1904, p. 62). ${ }^{5}$

Nas primeiras obras melodramáticas é marcante a representação de mitos fabulosos, sendo Euridice um texto composto em versos que podem ser alternados livremente, pois não há divisões precisas entre seus atos. Na prática, a encenação começa com um prólogo cantado que, posteriormente, se abre com pastores cantando em um ambiente campestre onde é celebrado o casamento de Orfeu e Eurídice. Não obstante, com o tempo, a utilização do argumento mitológico acabou dando espaço às representações de fatos históricos.

É indiscutível que a música sempre esteve presente nas diversas representações sacras do final da Idade Média, nas fábulas pastorais do Renascimento, no coro, tendo um papel fundamental na ação cênica. Entretanto, vale frisar que a forma musical mais expressiva e dominante até o século XVI era o madrigal ou madrigal dramático, um tipo de teatro de polifonia vocal intimamente ligado ao poema textual, no qual a música é usada como se fossem palavras para constituir uma representação com música e texto poético.

Neste tipo de apresentação, é patente a presença do canto polifônico que, como o próprio nome sugere, permite a expressão através de muitas vozes simultaneamente, apresentando grande dramaticidade; talvez seja essa característica que serviu de suporte para Balboni (2016) afirmar que a montagem dos primeiros melodramas se resumia apenas na reelaboração de um gênero de espetáculo já existente.

Uma modificação mais efetiva e evidente no gênero vai surgir somente em 24 de fevereiro de 1607, quando Claudio Monteverdi apresenta a fábula Orfeu no carnaval de Mântua. Com essa montagem, ele inaugura não apenas uma nova

${ }^{5}$ Cosi un gentiluomo mecenate offriva a proprie spese alla corte Medicea, né solo quella volta, quello spettacolo che nobili intelletti con studi indefessi e con amore vivo per l' arte avevano da un decennio assiduamente vagheggiato: la sera del 21 gennaio 1599 rimane omai la data sicura per la rappresentazione del primo melodramma. (Solerti, 1904, p. 62 - Tradução nossa). 
musicalidade para o gênero, mas passa a dar mais destaque para a parte teatral que colocou em cena o libreto de Alessandro Striggio Junior, sendo "mais que um sucesso, uma revelação, porque Monteverdi superou em muito também os mestres de Florência ao transpor para a música o sentimento da poesia”ø. (Solerti, 1904, p. 69).

Na época que montou Orfeu, Monteverdi já era conhecido pela composição de madrigais dramáticos, sendo recorrente que muitos autores, a exemplo de Kerman (1990), o indiquem como o último grande madrigalista e o primeiro grande compositor de ópera. De fato, Monteverdi realizou alterações significativas no modo de apresentação cênica e musical da época e, além de destacar particularidades na representação, dando maior força ao drama, fez notar o papel do compositor como o dramaturgo da obra.

A simbiose que surgiu entre o som da música e o texto do libreto evidenciou a possiblidade da expressão de sentimentos através da música, em um momento histórico em que a noção de experiência emocional ainda não existia, essa que, como indica Kerman (1990), só seria desenvolvida com o conceito moderno de coerência musical de Gluck, outro grande compositor de ópera que posteriormente também traria uma renovação para melodrama, ao realizar uma montagem da fábula de Orfeu em 1762, em Viena.

A expressividade musical conhecida até então, como indica Kerman (1990) concentrava-se em estados de espírito e imagens em apresentações de madrigais, e acrescenta:

Agora havia um ideal mais especificamente neoclássico: a música, em vez disso, deveria imitar as entonações do discurso apaixonado, que é melhor representado pela retórica grandiosa de um grande ator. A música deveria seguir a cadencia e, assim, a comovente implicação da palavra individual, dando pouca atenção à frase, à sentença, ou mesmo ao sentimento total. O resultado foi o recitativo, a emoção desordenada, um contínuo grito do coração, sem distanciamento, "a voz humana nua" por trás da voz cadenciada do poeta. Sua magnificência e seu imediatismo derivam exatamente de sua natureza impulsiva, de sua falta de controle formativo. (Kerman, 1990, p. 42).

${ }^{6}$ [P]iù che un successo, una rivelazione, perchè il Monteverdi superò d'assai anche i maestri fiorentini nel trasfondere nella musica il sentimento della poesia. (Solerti (1904, p. 69 - Tradução nossa). 
Destarte, com o recitativo ou recital cantado, Monteverdi renovou a relação entre o texto do libreto e a música no sentido dramático, sendo afetos e paixões unidos em uma situação dramática enriquecida pelo ato de recitar cantando, em que os versos de canto silábico possibilitavam cada nota recair sobre uma sílaba.

A inovação cênica iniciada no século XVI foi regida por diferentes fatores entre os quais se podem citar a utilização do estilo monódico, em que a composição musical se direciona ao uso de uma única voz, ao invés do canto polifônico e a invenção do baixo contínuo, que teve grande importância especialmente nas árias nas quais um único instrumento é colocado para realizar o acompanhamento vocal.

É importante marcar que até então a efervescência em torno do gênero ainda era reservada a espaços restritos, sendo o melodrama apresentado apenas nas cortes aristocráticas, pois ainda não existiam espaços convencionais para esse tipo de representação que, concebida para ser apresentada em dois atos, colocava música no intervalo, tanto para separar os atos quanto para distrair o público.

Somente em 1637 é inaugurado em Veneza o Teatro San Cassiano, o primeiro espaço aberto ao público pagante, com a encenação de L’Andromeda; além de pioneira, essa cidade italiana chegou a ter dezessete casas apropriadas a receber montagens de grandes dimensões, como as óperas melodramáticas.

As palavras exagero ou operístico talvez sejam os termos ideais para definir uma arte que une "enredos intricados, textos incompreensíveis, orquestração enfática, interpretação hiperbólica, encenação exótica, e cantores temperamentais" (Riding e Dunton-Downer, 2010, p.10) A ópera, de acordo com Riding e Dunton-Downer (2010), é uma experiência emocional à qual não se pode negar a essência teatral, que envolve uma história que proporciona junto com a música grande sentimentalidade.

A expressão emocional característica do melodrama, entretanto, não deve ser concebida como uma exclusividade do gênero, pois como os autores apontam o "ato de cantar - o amor, a traição, o sofrimento, ou a alegria - é mais antigo que a história documentada, inseparável das próprias paixões humanas. Assim, o que 
os primeiros criadores da ópera fizeram foi dar uma nova forma lírica e dramática a sentimentos imemoriais". (Riding e Dunton-Downer, 2010, p.10).

Ao longo da história o melodrama vai absorver muitas modificações que vão estabelecer diferenças marcantes na exibição desse gênero, que acabou sendo muito apreciado em diferentes países os quais não apenas o receberam, mas propuseram reelaborações e ressignificações que afirmaram inclusive o uso do próprio termo.

\section{Melodrama entre o mesmo e o novo}

Após empreender esse percurso, a compreensão de que o melodrama nasceu na Itália vinculado ao surgimento da ópera se torna clara. Essa informação é corroborada por diferentes autores, entre os quais se podem citar aqui JeanMarie Thomasseau (2005), que marca, inclusive, a existência de ambiguidades e de múltiplos sentidos em torno da origem do gênero, e Ivete Huppes (2000, p. 21) que destaca:

O gênero teatral conhecido como melodrama tem a origem associada à ópera. Na Itália, onde era de fato sinônimo de ópera; também se ligou à opereta e à ópera popular, que junta texto e canção, sendo conhecido desde o século XVII. Daí passou à França, atingindo então o estágio composicional que veio a conquistar o prestígio e a aceitação que the reconhecemos.

Vale marcar que até a primeira metade do século XVIII as apresentações melodramáticas reverenciavam, predominantemente, o gênero sério da ópera, fato que com o tempo mudaria quando o espaço dos pomposos recitais cantados passa a ser compartilhado com um tipo de apresentação mais cômica, a ópera bufa. Essa tipologia de espetáculo se caracterizou pela negação da presença de elementos que atribuíssem uma tonalidade heroica ao drama, argumento comum nas óperas sérias, sendo permitida a presença de personagens pitorescos como a cortesã indecorosa que era representada de modo verossímil utilizando a voz natural, sendo negada a atuação das refinadas vozes dos castrati. 
A ópera bufa criada no contexto italiano no século XVIII, mais especificamente em Nápoles, se destacou pela utilização do dialeto napolitano nas apresentações melodramáticas, que passaram a ser compreensíveis a uma quantidade maior de pessoas, quando a língua italiana utilizada nas óperas, até então, não era do conhecimento de todos. Essa mudança vai provocar a democratização do acesso a esse tipo de obra, que teve grande empatia do público não apenas por que o dialeto napolitano era utilizado nas apresentações, mas também por que os personagens representados se relacionavam com pessoas reais, distanciando-se dos fatos mitológicos, havendo uma ligação estrita, mesmo que não tão evidente, com a Comédia Dell'Arte pelo recurso ao uso de máscaras e de personagens tipo.

Com o gênero ópera bufa se destacaram exímios autores como, por exemplo, Giovanni Battista Pergolesi que vai se tornar importante, inclusive, no contexto francês. Na França, Pergolesi vai colocar em cena a ópera bufa La serva Padrona’ no entremeio da peça séria ll prigionier Superbo, também de sua autoria, marcando o acirramento de uma disputa que ficou conhecida como Querelle des Bouffons, que polarizou os defensores da ópera lírica e os apoiadores da ópera bufa. Dois grupos distintos vão surgir: um que defendia a ópera bufa italiana, considerando-a um trabalho diferenciado, com um modo de atuação mais atual, tendo o apoio dos Enciclopedistas, entre os quais Rousseau e Diderot, que buscavam à renovação da ópera lírica; e o outro que apoiava a ópera lírica, mantendo a preferência pelo gênero sério francês, tendo como principal referência o compositor Jean-Philippe Rameau.

O confronto entre a ópera bufa italiana e a ópera lírica francesa incentivou aos que defendiam a ópera italiana a se dedicarem à criação de uma ópera cômica francesa. Nesse sentido, ao realizar a montagem da ópera Le devin du village, como uma resposta francesa à obra de Pergolesi, Rousseau inicia as movimentações em torno da busca de modificações que só se tornariam evidentes posteriormente, em 1753, com a apresentação Des Troqueur, de Antonie Dauvergene, que colocou em cena diálogos falados que posteriormente acabariam

${ }^{7}$ La serva Padrona foi apresentada pela primeira vez em Nápoles em 28 de agosto de 1733, sendo o seu libreto publicado em Paris, em versão bilíngue, no ano de 1746. A encenação dessa ópera a Paris por Pergolesi vai acontecer seis anos depois, em 1752. 
se firmando também como uma característica na ópera cômica francesa.

Cabe destacar que a ópera cômica tem suas origens nas feiras parisienses onde era recorrente a exibição dos saltimbancos com números circenses como malabarismo, doma de animais, acrobacias, etc., e de companhias de teatro com a representação de pequenas comédias. Com o tempo, os saltimbancos e grupos teatrais passaram a trabalhar juntos em mini estabelecimentos, onde a música também se fez presente.

Essas apresentações eram muito apreciadas pelo público, mostrando-se em via de concorrência para com os teatros oficiais que detinham a permissão para apresentar certos tipos de peças. Diferentes proibições seguiam às exibições das companhias até o século XVIII, as quais se direcionaram à procura de soluções para problemas como podia ser o uso da fala fora das salas oficiais, revelando grande criatividade de acordo com o tipo de proibição recebida, como o uso de monólogos, cartazes, cenas mudas, pantomimas. E tudo isso acontecia por que:

$\mathrm{Na}$ França deste período, havia uma hierarquia entre os teatros, totalmente legitimada pelo poder político, onde ao Théâtre Royal cabiam as peças cantadas, à Comédie Française as integralmente declamadas e à Comédie Italianne, nos períodos em que ela existiu, os espetáculos em italiano. Neste cenário em que a concessão da fala estava nas mãos da Comédie Française e do canto do Théâtre Royal, os vaudevilles e depois as opéras-comiques sofreram inúmeras sanções, as quais foram fundamentais para a definição do gênero como tal. (Scandarolli 2012, p. 2-3).

As modificações em torno do gênero melodramático eram notáveis e continuaram se expandindo ao ponto de o termo ser usado como chamariz para o público que atendia com o nome de "melodrama, cômico ou pastoral, algumas peças curtas em um ato, mais apropriadamente ligadas à "ópera cômica" ou ao que hoje se chamaria opereta, que eram encenadas no Teatro des Beaujolais." (Thomasseau, 2005, p.17).

Os melodramas receberam forte influência por ocasião da Revolução (17891799), absorvendo características específicas diante da extensa popularização do gênero, que passou a ser encenado em diferentes contextos, assimilando 
diferentes denominações, uma vez que o uso de "qualquer trapalhada cênica [podia] ser classificada de melodramática. Graças a isso, podemos encontrar, então mágicas melodramáticas, cenas líricas e melodramáticas, melodramáticas e alegóricas, melodramas pantomimo-líricos etc." (Thomasseau, 2005, p.17, grifo nosso).

Com o fim da Revolução francesa, o gênero é motivado pela ampliação do público propenso a assistir as apresentações. De acordo com Thomasseau (2005) o édito de 1791 possibilitou que qualquer cidadão pudesse construir um teatro público e apresentar peças de qualquer tipo de gênero, sendo fundamental para a difusão do teatro melodramático, que se tornou acessível a uma parcela maior da sociedade francesa, caracterizando-se como um gênero popular.

A burguesia, detentora das casas de espetáculo, compreendeu a importância do melodrama não apenas pela efetiva movimentação contrária aos excessos do teatro da época, mas porque esse demonstrava a possibilidade de influir diretamente na sociedade, um teatro que foi impulsionado como educativo e foi aplaudido pelas classes populares que se viam, pela primeira vez, representadas.

O melodrama colocou em cena o drama e o gosto burguês e se distanciava, e muito, das apresentações realizadas na corte onde os temas heroicos ainda vigoravam. Assim, o gênero estava destinado a ser apreciado pela massa popular, ou seja, ser assistido por uma grande quantidade de pessoas, um teatro "de todos para todos", onde em embate com o mal o bem vence num final triunfante.

As diferentes modificações por que passou o melodrama permitiu a sua sobrevivência ao longo da história. Ele acabou sendo apresentado em diferentes lugares do mundo e aqui no Brasil esse gênero foi encenado em diferentes espaços, passando a fazer parte, inclusive, dos espetáculos dos circos-teatro.

O circo-teatro é uma modalidade de circo que foi muito comum no Brasil a partir os anos 1900, e se destaca pela heterogeneidade de seu espetáculo que, diferentemente de outros circos, apresenta não apenas os números circenses, mas também uma peça teatral, que pode ser de diferentes gêneros como 
pantomimas, comédia, mágica, melodrama, entre outros. Benjamim de Oliveira ${ }^{8}$, o palhaço negro, foi um dos primeiros circenses a colocar peças teatrais em cena no circo, tendo uma participação importante na constituição do circo-teatro brasileiro.

É interessante marcar que o circo brasileiro se consolidou em um contexto onde ocorria um constante intercâmbio com artistas vindos de países europeus. As diferentes experiências possibilitaram a assimilação de elementos vindos de outros lugares e também o enriquecimento do espetáculo com o conhecimento da cultura local, impulsionando uma criação própria.

A existência do circo-teatro relaciona-se com uma tendência que vinha acontecendo em muitos outros países, e que já foi possível visualizar, inclusive, na constituição do gênero melodramático, de juntar diferentes modalidades artísticas.

No século XIX, diferentes espaços se prontificavam a apresentar espetáculos mistos sendo comum ao público se reunir em teatros, cafés-concerto, ou outros lugares, para assistir "gêneros ligeiros dramáticos-musicais-coreográficos" em programações que podiam até trazer "versões mais complexas estruturalmente, mas com o mesmo caráter ligeiro, como revistas, burletas, mágicas e operetas. E esse mesmo público frequentava os circos, tanto em suas versões itinerantes quanto nas ocupações de teatros". (Pimenta, 2010, p.31).

As peças melodramáticas foram muito apreciadas pelo público do circoteatro, talvez pela própria maleabilidade do gênero que facilmente se adequou ao contexto do circo. Nesse contexto o melodrama ganhou nova classificação incorporando o adjetivo circense para compor, como indicado por Pimenta (2005, p. 24), uma "dramaturgia original, com um estilo de linguagem próprio: o Melodrama Circense, que atingia a plateia dos circos-teatros atendendo às necessidades de seu imaginário, com jovens apaixonados, vilões terríveis e angústias maternas, em uma linguagem brasileira”.

${ }^{8}$ Benjamim de Oliveira foi abordado em investigações de importantes pesquisadores brasileiros como, por exemplo, Daniel Silva (2004) e Ermínia Silva (2007), havendo uma extensa bibliografia a seu respeito. 
Pimenta (2005) não deixa clara a informação sobre qual seria a "linguagem brasileira”, agregada aos espetáculos do circo-teatro nas apresentações dos melodramas circenses, mas é possível supor que sejam os próprios textos dramatúrgicos que, aos serem escritos pelos circenses, se apresentavam como um novo elemento, como indicado por Silva (2007):

Apesar da presença de produções europeias nos circos brasileiros, os circenses introduziram em seus espetáculos a presença nacional, tanto textos da dramaturgia como do romance-folhetim. É o caso da ópera em três atos O fantasma branco, de Joaquim Manuel de Macedo. (Silva, 2007, p. 109).

O romance de folhetim compôs a dramaturgia de muitas apresentações melodramáticas no circo-teatro, sendo um gênero que ofereceu grande contribuição à sua divulgação. Além disso, cabe notar o nome da obra a ser apresentada, O fantasma branco, que como indicado pela própria autora, é do gênero ópera, fato que demonstra a existência da possibilidade de o gênero ter sido utilizado no circo-teatro, como concebido em sua origem.

Neste ponto, cabe indicar a aproximação existente entre o romance de folhetim brasileiro e o romance d'appendice italiano, muito utilizado nas composições de ópera, nas quais se viam histórias que destacavam a justiça reparadora ou reivindicadora e onde a classe burguesa propunha os próprios valores. Esses temas tiveram espaço notável em muitas apresentações, se mantendo posteriormente como uma característica do melodrama.

Por sua vez, o romance d'appendice se liga ao romance de folhetim francês, que muito influenciou o contexto italiano com suas histórias, e, como diz Meyer (1997) ao falar sobre as histórias contadas por italianos imigrantes:

por mais estranho que possa parecer, a literatura popular francesa do século XIX, ou seja o romance-folhetim, foi a forma romanesca mais apreciada e conhecida na Itália do século XIX, na ausência de uma literatura nacional-popular própria. [...] o romance-folhetim francês do século XIX que os italianos denominam 'romanzo di appendice'. (Meyer, 1997, p. 80). 
Mesmo com toda fluidez e adaptabilidade, é importante marcar que o gênero melodramático guarda em si indicadores determinantes para a sua configuração, como uso do exagero, as relações de oposição entre bem e mal, a descoberta, final apoteótico, além de outros elementos que aparecem na configuração dos personagens, como tipos, a exemplo, o vilão, a vítima ingênua, o cômico.

Todas essas características se fazem importantes numa história melodramática, mas vale reforçar também a ideia de que o melodrama se direciona a apresentar aquilo que funciona para o público, não obedecendo aos limites de verossimilhança. De modo semelhante, ao circo-teatro interessa a realização de um espetáculo que funcione para a plateia, sendo essa uma característica do melodrama que encontrou no circo grande possibilidade de adaptação e difusão do gênero.

\section{Conclusões}

O presente artigo se direcionou à discussão do melodrama, destacando a sua grande adaptabilidade e mutabilidade ao longo da história, que possibilitou a sua existência em diferentes contextos. Questões que se respaldaram a partir do termo, conduziram a investigação para um momento histórico onde a sua constituição estética encontrou firmação na música em experimentações e apresentações da ópera, ressaltando a sua capacidade de suscitar emoções e sentidos, em uma dramaturgia que uniu poeta e compositor.

As diferentes experiências promovidas na exploração de diferentes campos artísticos, como o teatro, a dança e a música, projetaram um leque de possibilidades que ora destacou a voz, ora a música, ora elementos dramáticos, demonstrando a adaptabilidade do gênero.

A criação do gênero acontece na Itália, mas este foi concebido como drama cantado, ópera, espetáculo que mistura teatro, dança, música, em dramaturgias que, posteriormente, atingem diferentes partes do mundo. Na França o melodrama se difundiu, se diferenciou, recebendo novas conotações, 
principalmente por ocasião da revolução francesa.

Das pomposas exibições na corte às exibições do gênero ligeiro, o melodrama foi apreciado e aplaudido em diferentes países, que o recebeu como gênero espetacular, adaptando-o ao gosto do público para o qual se direcionava, valendose seja da ideia do simples divertimento, ou mesmo como produto direcionado ao ensino, sendo muitas vezes utilizado como instrumento.

Os lugares onde era apresentado o melodrama são múltiplos, e abrangem não apenas as casas de ópera, os teatros, mas também os circos-teatro. Com um espetáculo que envolve além dos números circenses uma representação dramática, o circo-teatro foi muito valorizado pelas representações de melodramas criando, inclusive, uma variedade própria, chamada de melodrama circense.

O melodrama circense, atendendo a ansiedade de um público que queria ver paixões desmedidas em histórias onde terríveis vilões pagavam o preço pelos seus atos, em final apoteótico, acabou divulgando o gênero teatral, para uma população muito diversificada, mesmo que distante do circuito das grandes casas de espetáculos. Assim, do teatro italiano à corte francesa, o melodrama chega ao Brasil e tem grande destaque nos espetáculos do circo-teatro, onde também se difundiu, confirmando a positividade de sua adaptabilidade, que possibilitou a sua permanência ao longo do tempo.

\section{Referências}

BALBONI, Paolo. Il Melodrama (in) Italiano. Turim: Loescher Editora, 2016.

HUPPES, Ivete. Melodrama: o gênero e sua permanência. São Paulo: Ateliê Editorial, 2000.

KERMAN, Joseph. A ópera como drama. Jorge Zahar Editor: Rio de Janeiro, 1990.

MEYER, Marlyse. Imigrantes italianos e leituras comunitárias. Revista Mediações Edição especial: Londrina, p.79-89, 1997.

MILA, Massimo. Il melodramma italiano dell'Ottocento. Torino: Einaudi, 1977. 
PIMENTA, Daniele. A conformação do circo-teatro brasileiro: permeabilidade e apropriação. Repertório, Salvador, ano 13, n. 15, p 30-39, 2010.

RIDING, Alan; DUNTON-DOWNER, Leslie. Guia Ilustrado Zahar. Ópera. Rio de Janeiro: Jorge Zahar Ed., 2010.

SCANDAROLLI, Denise. Estruturação do gênero "cômico" no Teatro Francês: Vaudeville e Opéra-Comique. Disponível em: http://www.encontro2012.sp.anpuh.org/resources/anais/17/1342532421_ARQUIVO_ OsgeneroscomicosdaOperaFrancesa.pdf. Acesso em: 09 jun. 2020.

SILVA, Daniel Marques. O palhaço negro que dançou a chula para o Marechal de Ferro: Benjamim de Oliveira e a consolidação do circo-teatro no Brasil mecanismos e estratégias artísticas como forma de integração social na Belle Époque carioca. Tese (Doutorado em Teatro). Centro de Letras e Artes. UNIRIO, Rio de Janeiro, 2004.

SILVA, Erminia. Circo-teatro: Benjamim de Oliveira e a teatralidade circense no Brasil. São Paulo: Altana, 2007.

SOLERTI, Angelo. Gli Albori del Melodramma. Milano-Palermo-Napoli: Libraio della Real Casa, 1904.

THOMASSEAU, Jean-Marie. O melodrama. São Paulo: Perspectiva, 2005.

Recebido em: 24/06/2020

Aprovado em: 30/09/2020

Universidade do Estado de Santa Catarina - UDESC

Programa de Pós-Graduação em Teatro - PPGT

Centro de Arte - CEART

Urdimento - Revista de Estudos em Artes Cênicas

Urdimento.ceart@udesc.br 